\title{
A New Era for Truncal Acne: Emerging from a Legacy of Neglect
}

Jerry K. L. Tan · Thomas Dirschka

Received: March 5, 2021 / Published online: April 20, 2021

(C) The Author(s) 2021

Keywords: Truncal acne; Acne; Acne vulgaris; Acne consultations; Topical treatment

\section{J. K. L. Tan}

Faculty of Medicine, Western University, London, ON, Canada

\section{T. Dirschka}

CentroDerm Clinic, Wuppertal, Germany

T. Dirschka

Faculty of Health, University of Witten-Herdecke, Witten, Germany

\section{J. K. L. Tan (ه)}

Windsor Clinical Research Inc., 2224 Walker Rd, Suite 300, Windsor, ON N8W5L7, Canada e-mail: jerrytan1230@outlook.com

\section{Key Summary Points}

Truncal acne, despite its prevalence, physical and psychological burden, has largely been neglected in prior clinical trials and guidelines.

Recognizing and addressing this shortcoming may reduce the overall burden of acne.

The potential effectiveness of some topical treatments in truncal acne challenge the role of systemic agents.

High-quality studies in truncal and facial acne are needed to expand the evidence base and inform treatment decisions.

In clinical practice, the evaluation and management of both facial and truncal acne, as well as exploring the overall burden, can address the comprehensive needs of our patients.

\section{DIGITAL FEATURES}

This article is published with digital features, including a summary slide, to facilitate understanding of the article. To view digital features 
for this article go to https://doi.org/10.6084/ m9.figshare.14346269.

\section{COMMENTARY}

Approximately $50 \%$ of patients with facial acne also present with lesions on the trunk (back and/or chest) [1], so why have clinical trials focused on the face for the past 50 years?

Truncal acne can place a considerable physical and psychological burden on patients, leading to pain, acne scars, and concerns over body image and physical appearance [2]. Despite this, it can be overlooked in consultations and undertreated. Here, we address the central role of open communication, the impact of limited clinical guidance, and the importance of treatment adherence to shed light on how to fill this gap.

Truncal acne is not always included in acne consultations. Currently, the main challenges to identifying truncal acne include limited time during consultations, inconvenience and/or reluctance of some patients to reveal parts of their body, and prioritization of facial acne. In our experience, an average acne consultation may only be a few minutes in duration, exemplifying the time pressure faced by dermatologists. Social/cultural barriers can prevent patients from openly discussing their truncal acne or revealing acne-prone areas of the body to their dermatologist. Moreover, truncal acne may not be a priority for patients when it is mild, and some may feel ashamed to initiate the conversation when it is moderate to severe. It is worth noting that even patients with mild facial acne can have moderate to severe acne on the trunk, and thus facial acne severity may not always correlate with that on the trunk.

Comprehensive evaluations that are inclusive of the trunk can provide a more accurate assessment of acne, and encouraging dialogue on the impact of acne can provide a holistic profile of the acne patient. In our experience, the presence of female assistants in consultations with male practitioners can help some patients feel more comfortable and encourage dialogue. Moreover, the use of photographs of their truncal acne, taken privately in the comfort of their own homes, may help patients feel more secure and less exposed during examinations. These images can be stored on protected sites or on the patient's camera/phone to protect their privacy. Equally, the introduction of teledermatology services may help overcome some of the social and cultural challenges of examining truncal acne, as well as the difficulties faced during a global pandemic when patients cannot visit their dermatologist's office. However, photos must be of high quality and teledermatology should not replace face-toface consultations, when possible, as they cannot depict the three-dimensional nature of some acne lesions.

Historically, truncal acne has been neglected in scientific investigation-and thus in the literature-with no specific diagnostic or treatment guidelines and a lack of robust and wellcontrolled clinical trials [3]. Indeed, benzoyl peroxide (BPO) washes have been the historical standard of care for truncal acne treatment despite the lack of randomized, controlled trials [4]. Moreover, even though several acne grading scales exist, few involve evaluations of truncal acne and none are universally used [5]. Exploring various clinical and quality of life (QoL) measures, such as the Physician Global Assessment (PGA) score, Leeds scale, Comprehensive Acne Severity Scale (CASS), lesion counts, and Comprehensive Quality-of-Life Measure for Facial and Torso Acne (CompAQ), is prudent for a comprehensive evaluation of truncal acne severity.

In our experience, key challenges in truncal acne are that patients can feel stigmatized by their condition and by the problems associated with their treatments, leading to poor adherence. Some patients feel that it is easier and more convenient to take a pill than to apply a potentially greasy, topical cream that may cause bleaching (in the case of BPO) over large body areas like the back, which may be inaccessible and have dispersed lesions. Some with severe truncal acne may feel uncomfortable using topical treatments, as they do not want to touch their lesions, nor want to be dependent on others touching them during treatment application. It is worth noting that deep, inflammatory truncal lesions can be painful and far worse 
than those of facial acne, particularly where lesions are in contact with clothing, including undergarments. Furthermore, the perceived difficulty in adhering to treatment and the lack of awareness concerning treatment options mean that both dermatologists and patients may avoid talking about treatment altogether. We have typically relied on systemic treatments like isotretinoin or oral antibiotics to treat inflammatory lesions on the trunk; however, further exploration of topical treatments is necessary to expand the pool of available treatment options for truncal acne. This includes considering alternatives to systemic treatments and more convenient application approaches for topical treatments.

One of the most prominent unmet needs in truncal acne is the relative lack of communication about that region of involvement compared to facial acne, with limited enquiry from dermatologists and initial declaration by patients. There is also a need for evidence-based treatments that address both the psychological and physical sequelae of truncal acne. Recent advancements with topical treatments provide much needed hope to fill this gap. Despite the lack of robust clinical evidence, the introduction of azelaic acid foam and tretinoin lotion formulations challenge the need for isotretinoin or oral antibiotics for the treatment of truncal acne. Clinical trials for trifarotene $(50 \mu \mathrm{g} / \mathrm{g})$ cream were specifically designed to evaluate its role in both facial and truncal acne [6, 7]. Welldesigned, large-scale studies such as these will further expand current knowledge on truncal acne treatment. In the meantime, we must think and act beyond the scope of currently available guidance and ensure that truncal acne is part of every acne consultation and follow-up.

\section{ACKNOWLEDGEMENTS}

Funding. Galderma funded the Rapid Service Fee.

Medical writing and/or Editorial Assistance. Medical writing support was provided by Dr Arti Sikka (Publicis Langland). This assistance was funded by Galderma.

Authorship. All named authors meet the International Committee of Medical Journal Editors (ICMJE) criteria for authorship for this article, take responsibility for the integrity of the work as a whole, and have given their approval for this version to be published.

Authors' Contributions. Professors Jerry Tan and Thomas Dirschka drafted the manuscript.

Disclosures. Professor Tan is an advisor, consultant, investigator and/or speaker and received grants and honoraria from Almirall, Bausch, Botanix, Boots Walgreens, Cipher, Galderma, Novartis, Sol-Gel, Sun, and Vichy. Professor Dirschka has received research support and/or lecture fees and/or is an advisory board member for Almirall, Biofrontera, Dr. Pfleger, Galderma, GSK, Infectopharm, Janssen-Cilag, Leo, Meda, Neracare, Novartis, Riemser, and Scibase.

Compliance with Ethics Guidelines. This article is based on previously conducted studies and does not contain any new studies with human participants or animals performed by any of the authors.

Open Access. This article is licensed under a Creative Commons Attribution-NonCommercial 4.0 International License, which permits any non-commercial use, sharing, adaptation, distribution and reproduction in any medium or format, as long as you give appropriate credit to the original author(s) and the source, provide a link to the Creative Commons licence, and indicate if changes were made. The images or other third party material in this article are included in the article's Creative Commons licence, unless indicated otherwise in a credit line to the material. If material is not included in the article's Creative Commons licence and your intended use is not permitted by statutory regulation or exceeds the permitted use, you will need to obtain permission directly from the copyright holder. To view a copy of this licence, 
visit http://creativecommons.org/licenses/by$\mathrm{nc} / 4.0 /$.

\section{REFERENCES}

1. Del Rosso JQ, et al. A closer look at truncal acne vulgaris: prevalence, severity, and clinical significance. J Drugs Dermatol. 2007;6(6):597-600.

2. Hassan J, et al. The individual health burden of acne. J Health Psychol. 2009;14(8):1105-18.

3. Asai $Y$, et al. Management of acne: Canadian clinical practice guideline. CMAJ. 2016;188:118-26.
4. Bikowski J. A review of the safety and efficacy of benzoyl peroxide $(5.3 \%)$ emollient foam in the management of truncal acne vulgaris. J Clin Aesthet Dermatol. 2010;3(11):26-9.

5. Liu C, Tan J. Understanding truncal acne: a practical guide to diagnosis and management. Skin Ther Lett. 2017.

6. Tan J, et al. Randomized phase 3 evaluation of trifarotene $50 \mu \mathrm{g} / \mathrm{g}$ cream treatment of moderate facial and truncal acne. J Am Acad Dermatol. 2019;80(6):1691-9.

7. Blume-Peytavi $U$, et al. Long-term safety and efficacy of trifarotene $50 \mu \mathrm{g} / \mathrm{g}$ cream, a first-in-class RAR- $\gamma$ selective topical retinoid, in patients with moderate facial and truncal acne. J Eur Acad Dermatol Venereol. 2020;34(1):166-73. 